\title{
Expanding the envelope: linking invertebrate bioturbators with micro-evolutionary change
}

\author{
Deena Pillay*
}

Marine Research Institute, Zoology Department, University of Cape Town, PB X3, Rondebosch 7701, South Africa

\begin{abstract}
Research on the influence of bioturbators has advanced considerably over the last decade. Their link to evolutionary change, especially their hypothesized role in the Cambrian explosion, has generated particular interest. This macro-evolutionary link, however, only partially reveals the role of bioturbators in evolution. A closer inspection of the literature shows that bioturbators may potentially play a greater role in this regard, especially at the micro-evolutionary scale, in which they indirectly influence the selective pressure on co-occurring species and, consequently, the evolution of novel morphologies, behavioural and social interactions. Such effects are absent in current thinking, but need to be integrated in order to reveal the full sphere of influence of bioturbators.
\end{abstract}

KEY WORDS: Bioturbation · Evolution · Elite structures · Cambrian explosion · Symbiosis

The role of organisms in structuring aquatic and terrestrial communities has been emphatically demonstrated throughout the world. Recent research has also shed light on their roles as ecosystem engineers, in which they directly or indirectly modulate resource flow to other species via physical changes in their environments (Jones et al. 1994). Organisms may, however, play an additional role; they may theoretically affect the evolution of their own and other co-inhabiting species (Odling-Smee et al. 2003). Many organisms produce constructs such as burrows, nests, tubes or tunnels, and in so doing, define, create and modify their own niches and those of others, thereby influencing the selective pressures operating on future generations of their own and other co-occurring species by setting up feedback loops (Odling-Smee et al. 2003).

Invertebrates that burrow in marine soft-sediment ecosystems are prime examples of organisms that modify their ecosystems, either through their physical constructs or enhanced particle or solute transport. Their reworking of sediments is generally referred to as bioturbation (Meysman et al. 2006), and is linked to various alterations of the sedimentary environment and overlying water column (reviewed by Bromley 1996), with important consequences for co-occurring sediment communities. Bioturbation by burrowing invertebrates is intrinsically linked with burrow construction and maintenance.

Over the last decade, bioturbating organisms have emerged as major factors in ecology and evolution. The association between bioturbators and evolutionary change is an important area of advance, especially the hypothesised connection with the Cambrian substrate revolution (Meysman et al. 2006). In brief, it is hypothesised that the evolution of burrowing organisms played a role in the transition between pre- and postCambrian life on the seafloor. Pre-Cambrian sediments were covered by well-developed microbial mats, which were the major structuring agents of sedimentary life at the time. The evolution of burrowing invertebrates, however, led to the gradual destruction of these mats, which were replaced by mixed sediments with greater biochemical heterogeneity, which in turn is hypothesised to have led to the diversification 
of benthic metazoan life through a runaway evolutionary event (Meysman et al. 2006). This association is currently the most well-known link between bioturbators and evolutionary change.

While this macro-evolutionary link is of extreme significance, it only partially reveals the sphere of influence of bioturbators on the evolutionary stage. The role of these organisms in micro-evolutionary change, however, remains largely unexplored, and is presently absent in current thinking when attempting to link bioturbation with evolution. Although scattered and sometimes not in the primary scientific literature related to bioturbation, there is compelling evidence that bioturbating organisms may influence other species at the micro-evolutionary level, in both terrestrial and aquatic ecosystems, leading to evolutionary changes in morphology, behaviour and social interactions (Hansell 1993, Bromley 1996, Eisenberg \& Kinlaw 1999, Hafner et al. 2000). Each of these aspects occurs in response to the presence of burrow systems in sediments and/or the movement of particles by bioturbators. The evolution of interspecific communication systems may also occur when social interactions between bioturbators and co-occurring species become prominent.

The burrows constructed by bioturbators may potentially offer several advantages to other organisms (Bromley 1996). Firstly, organisms may avoid dangers associated with the pelagic environment, such as predators, turbulence and periodic exposure during low tides. In instances where bioturbators turn over sediment rapidly (e.g. thalassinids), their burrows may provide a refuge to other species from expelled sediment. Secondly, water can be circulated relatively easily through burrows without much energy expenditure, making ventilation of the gills and respiratory surfaces comparatively easy, offering an elegant solution to the problem of sediment anoxia. The relative ease of generating currents in burrows could also be exploited to aid filter feeding, and burrows may protect the bodies of deposit feeders while specialised appendages are used to collect organic matter on the sediment surface. Lastly, burrows may aid in feeding by having specialised regions for 'gardening' of microbes (Bromley 1996).

These 'elite structures' (Bromley 1996) are therefore major attractants to other species, because of the advantages they offer and their unique biogeochemical characteristics, often leading to shared use of burrows and the evolution of elaborate symbiotic assemblages (Eisenberg \& Kinlaw 1999, Hafner et al. 2000). In marine ecosystems, this is typified by the inn-keeper worms, a group which is so named because of the 'guests' they house in burrows, including species of goby, scale-worm and crab (Anker et al. 2005). Similar situations exist in terrestrial ecosystems where armadillo, gopher tortoises and pocket gophers, for example, house various commensal associates (Eisenberg \& Kinlaw 1999). The literature on commensal associations with bioturbating species is vast, with relationships ranging from facultative to obligate. It is in the obligate groups, i.e. those that are entirely dependent on the host and its burrow, that the most radical changes in commensal morphology evolve, as is evidenced by the loss of eyes in the blind goby Typhlogobius californiensis (MacGinitie 1939) or the loss of a pair of walking legs in the 6-legged crab Spiroplax spiralis (Branch et al. 1994, Fig. 1). Blind gobies live in deeper portions of the host burrow, and the absence of light likely accounted for the evolutionary loss of eyes (MacGinitie 1939). Newly hatched gobies have fully developed eyes, but as they grow, their retinas change shape, become withdrawn and covered by the body layers, giving the gobies their eyeless appearance. The gobies cannot burrow by themselves, and are entirely reliant upon their hosts to generate currents to bring in food. In the case of the 6-legged crab, this commensal organism lies compressed against burrow walls, allowing the host to pass without the crab being detected. The precise agent selecting for the loss of a pair of legs in this crab is unclear, but is most likely linked to its commensal mode of existence.

Behavioural changes may also evolve due to the burrows produced by bioturbators, as is evident in the divergence of feeding behaviour of commensal species. The commensal clam Cryptomya californica for example, feeds by inserting its siphons into the burrows of their hosts, which are usually thalassinids, and

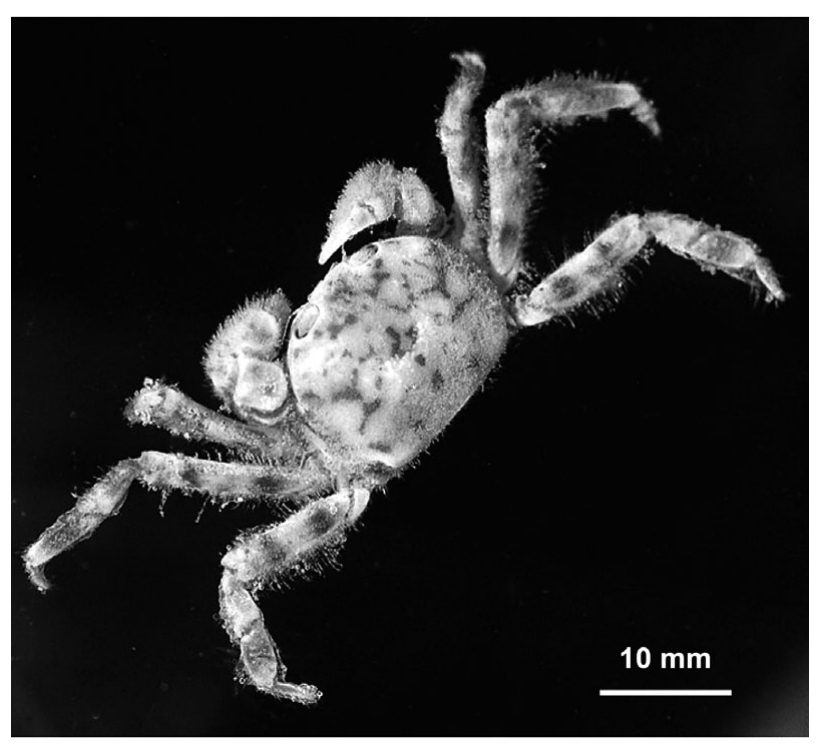

Fig 1. Dorsal view of the commensal 6-legged crab Spiroplax spiralis (photo: G. M. Branch) 
filters the circulating burrow water. Free-living species, on the other hand, filter the overlying water column (MacGinitie 1934). This behavioural adaptation allows the clam to live deeper in the sediment away from predators, while optimising its feeding. In another extreme example, the commensal filterfeeding bivalve Peregrinamor ohshimai attaches directly to its host, a filter-feeding mudshrimp, and inserts its siphons into the host's filtering basket (Kato \& Itani 1995), thereby maximising feeding by taking advantage of the superior pumping action of the host. Burrow associates are also known to link their burrows to the host burrow, thereby preventing direct contact with their hosts, but producing incredible complex structures in the process (Bromley 1996). Such combined structures are produced by the lobster Nephrops norvegicus, the goby Lesuerigobius friesii and the crab Goneplax rhomboides (Atkinson 1974).

Finally, the co-evolution of hosts and burrow symbionts may lead to the development of complex social interactions (Karplus 1987, Hansell 1993). This is most evident in the intricate warning relationships that are common in marine ecosystems, and is exemplified by shrimp-goby associations. In this relationship, gobies and burrowing shrimp share burrows in a mutually beneficial manner (Karplus 1987), in which the shrimp provides refuge for the goby in the form of a burrow, while the goby acts as a scout, signalling the presence of danger. In these associations, complex interspecific communication may evolve, and in the shrimp-goby warning relationship, this involves quick head-first entries into burrows and rapid tail flicks by the goby. Shrimp, in turn, receive signals by placing their antennae onto the body of the fish (Karplus 1987).

These few examples illustrate the potential influence of bioturbators on evolutionary change. The physical presence of burrows, allied with particle movement, may have been important drivers of shared use of burrows and subsequent diversification. Incorporating such ideas into current thinking may expand the field of bioturbation research, possibly providing new links between bioturbators and micro-evolution. The application of molecular techniques may offer an opportunity to provide quantitative information on such links. Phylogeny estimation for example, when combined

Editorial responsibility: Matthias Seaman, Oldendorf/Luhe, Germany with ecological studies, can provide important information on the evolution of interacting lineages (Brooks \& McLennan 1991, Chenuil \& McKey 1996).

\section{LITERATURE CITED}

Anker A, Murina G, Lira C, Vera Caripe JA, Palmer AR, Jeng M (2005) Macrofauna associated with echiuran burrows: a review with new observations of the innkeeper worm, Ochetostoma erythrogrammon Leuckart and Rüppel, in Venezuela. Zool Stud 44:157-190

> Atkinson RJA (1974) Spatial distribution of Nephrops burrows. Estuar Coast Mar Sci 2:171-176

Branch GM, Griffiths CL, Branch ML, Beckley LE (1994) Two oceans, a guide to the marine life of southern Africa. David Phillip Press, Cape Town

Bromley RG (1996). Trace fossils. Biology, taphonomy and applications. St Edmudsbury Press, Suffolk

Brooks DR, McLennan DA (1991) Phylogeny, ecology and behaviour, University of Chicago Press, Chicago, IL

> Chenuil A, McKey DB (1996) Molecular phylogenetic study of a myrmecophyte symbiosis: Did Leonardoxa/ant associations diversify via cospeciation? Mol Phylogenet Evol 6: $270-286$

- Eisenberg JF, Kinlaw A (1999) Introduction to the Special Issue: ecological significance of open burrow systems. J Arid Environ 41:123-125

Hafner MS, Demastes JW, Spradling TA (2000) Coevolution and subterranean rodents. In: Lacey EA, Patton JL, Cameron GN (eds) Life underground: the biology of subterranean rodents. University of Chicago Press, Chicago, IL

Hansell MH (1993) The ecological impact of animal nests and burrows. Funct Ecol 7:5-12

Jones CG, Lawton JH, Shackak M (1994) Organisms as ecosystem engineers. Oikos 69:373-386

Karplus I (1987) The association between gobiid and burrowing alpheid shrimps. Oceanogr Mar Biol Annu Rev 25: 507-562

Kato M, Itani G (1995) Commensalism of a bivalve, Peregrinamor ohshimai, with a thalassinidean burrowing shrimp, Upogebia major. J Mar Biol Assoc UK 75:941-947

> MacGinitie GE (1934) The natural history of Callianassa californiensis Dana. Am Midl Nat 15:166-177

MacGinitie GE (1939) The natural history of the blind goby Typhlogobius californiensis Steindachner. Am Midl Nat 21:489-505

> Meysman FJR, Middelburg JJ, Heip CHR (2006) Bioturbation: a fresh look at Darwin's last idea. Trends Ecol Evol 21: 688-695

Odling-Smee FJ, Laland KN, Feldman MW (2003) Niche construction. The neglected process in evolution. Princeton University Press, Princeton, NJ

Submitted: February 12, 2010; Accepted: April 19, 2010

Proofs received from author(s): June 17, 2010 